\title{
Evaluation of nutritional conditions, haemoglobin levels, retention in care and viral suppression in a cohort of HIV-infected Malawian adolescents undergoing a one-year tailored intervention within the Diseases Relief through Excellence and Advanced Means programme
}

\author{
F Ciccacci, ${ }^{1} \mathrm{MD}$, PhD; S Orlando, ${ }^{2} \mathrm{PhD}$; J B Sagno, ${ }^{3} \mathrm{MD} ;$ M Kamponda, ${ }^{3} \mathrm{BSc} ; \mathrm{J}$ Gondwe, ${ }^{3} \mathrm{BSc} ; \mathbf{R}$ Lunghi, ${ }^{4} \mathrm{PhD}$; \\ M C Marazzi, ${ }^{5} \mathrm{MD} ;$ L Palombi $^{2} \mathrm{MD}$ \\ ${ }^{1}$ UniCamillus, International University of Health and Medical Science, Rome, Italy \\ ${ }^{2}$ Department of Biomedicine and Prevention, University of Rome Tor Vergata, Rome, Italy \\ ${ }^{3}$ Diseases Relief through Excellence and Advanced Means Program, Community of Sant'Egidio, Blantyre, Malawi \\ ${ }^{4}$ Diseases Relief through Excellence and Advanced Means Program, Community of Sant'Egidio, Rome, Italy \\ ${ }^{5}$ LUMSA, Rome, Italy
}

Corresponding author: F Ciccacci (fausto.ciccacci@gmail.com)

\begin{abstract}
Background. The United Nations Children's Fund (UNICEF) reported that 1770000 adolescents were living with HIV infection in 2017, of whom $>80 \%$ were in sub-Saharan Africa. In Malawi, 25000 boys and 46000 girls are infected with HIV.

Objective. The present study aimed to evaluate a specific adolescent-friendly service implemented in a Diseases Relief through Excellence and Advanced Means (DREAM) health centre in Malawi.

Methods. All HIV-positive patients aged 10 - 19 years in the care of the DREAM centre in Blantyre on 17 December 2016 were included in the study and followed-up until 1 January 2018. The service was organised for one adult-free day, with some side activities managed by a co-ordinator and youth leaders. Assessments were performed at the end of the period (EOP).

Results. On 17 December 2016, 425 patients were enrolled in the study. Follow-up status at EOP was 403 (94.8\%) patients in care, 7 (1.6\%) lost to follow-up (LTFU), 2 (0.5\%) died and 13 (3.1\%) were transferred to other facilities. Death and LTFU rates were 0.72/100 and 2.9/100 person-years, respectively. Moreover, 50.6\% $(n=198 / 391)$ of patients had an improvement in body mass index (BMI)-for-age $z$-scores, and $70.2 \%(n=33 / 47)$ of patients who were malnourished at baseline improved (higher improvement in older patients). Mean (standard deviation (SD)) haemoglobin levels increased from 12.5 (1.5) $\mathrm{mg} / \mathrm{dL}$ to 13.1 (1.9) $\mathrm{mg} / \mathrm{dL}$ (significance level $p=0.000)$. At the EOP, 79.0\% ( $n=309 / 391)$ of patients had viral suppression.

Conclusion. Care of adolescent HIV+ patients remains a challenge, but the implementation of specific projects involving adolescents and youth leaders can increase adherence and improve viral suppression.
\end{abstract}

S Afr J Child Health 2020;14(3):228-232. https://doi.org/10.7196/SAJCH.2020.v14i3.1751

The United Nations Children's Fund (UNICEF) reported that $\sim 1770000$ adolescents were living with HIV infection worldwide in $2018 .{ }^{[1]}$ In the same year, 590000 young patients aged $15-24$ years became infected with HIV ${ }^{[1]}$ Moreover, in 2016, the Joint United Nations Programme on HIV/AIDS (UNAIDS) reported that adolescents aged $10-19$ years is the only age group in which deaths related to HIV infection are not reducing. ${ }^{[2]}$

HIV infection in adolescents is one of the major challenges for health sectors in sub-Saharan Africa (SSA), as $>80 \%$ of HIV-positive young patients aged $10-19$ years live in this region. ${ }^{[3]}$ The number of HIV-positive adolescents is expected to increase in the future mainly due to a combination of two factors: new infections in adolescents, and the widespread use of paediatric antiretroviral treatment (ART) that will result in HIV-positive children survive and age.

Adherence to ART is still a global challenge, ${ }^{[4,5]}$ especially in HIV-positive adolescents. ${ }^{[6]}$ Although better outcomes have been reported in SSA than in Europe and North America, ${ }^{[7]}$ attrition remains a challenge in HIV care programmes for adolescents in many countries in SSA. ${ }^{[8-10]}$ Poor adherence is related to worse general outcomes and scarce control of viral replication. ${ }^{[11,12]}$ This could have several consequences from a public health perspective: increasing transmission rates in the population, the circulation of resistant strains, and an increase in patients needing to switch to second- or third-line treatment. ${ }^{[13,14]}$

There is an urgent need to design programmes that offer more effective interventions to reach a high number of HIV-positive adolescents.

Malawi is one of the countries most severely affected by HIV, with a prevalence of $9.2 \%$ in people aged 15 - 49 years, ${ }^{[15]}$ and where $\sim 25000$ boys and 46000 girls aged 10 - 19 years are infected with HIV ${ }^{[2]}$

Although interventions that were intended to improve adherence have been widely evaluated, ${ }^{[16-18]}$ evidence on the outcomes of specific adolescent-friendly interventions is scarce. ${ }^{[19]}$ The present study aimed to evaluate a specific adolescent-friendly service implemented 
in a health centre in Malawi within the Diseases Relief through Excellence and Advanced Means (DREAM) programme.

\section{Materials and methods}

We conducted a retrospective analysis of routine electronic medical records of adolescent patients in the care of the DREAM centre in Blantyre, Malawi. The DREAM programme is a public health programme run by the Community of Sant'Egidio in 11 countries in SSA. The programme focuses on HIV prevention, care, and retention strengthening. ${ }^{[20-22]}$

\section{Site description}

The Blantyre DREAM health centre has been active since 2006, with a total of $5081 \mathrm{HIV}$-positive patients currently in care. A number of the services offered are: prevention of mother-to-child transmission, provider-initiated testing and counselling, HIV testing and counselling, tuberculosis diagnosis and treatment, cervical cancer screening and treatment, non-communicable disease screening and treatment (hypertension, kidney disease and diabetes), HIV care, health education, sensitisation in communities, and home care visits. ${ }^{[21,23,24]}$

\section{Intervention description}

The new adolescent-centred service at the DREAM facility in Blantyre started on 17 December 2016. Once a month (last Saturday of the month), the centre is open solely for adolescents, and the activities are managed by a coordinator who operates in partnership with some youth leaders. The latter are HIV-positive individuals aged 18 - 24 years who are involved in the centre. Youth leaders are a cornerstone of the service, as they are peer-to-peer educators performing several activities (sensitisation of fellow adolescents at the centre and in schools and communities, counselling of peers with drug-addiction problems, disclosure of HIV status). Their role is intended to be like that of an older brother or sister for the HIVpositive adolescents receiving care.

On the 'adolescent day', many activities are conducted. Clinical services are available only for adolescent patients: medical examination, medical counselling, blood sampling, exams review, drug refill. At the same time, many non-clinical activities are carried out. HIV-positive adolescents are involved in many events both in the centre and outside. For the non-clinical activities, patients are usually grouped according to age, to achieve better and more accessible communication. Some of the activities conducted are teen clubs, role play and organisation of outreach sensitisation activities. Topics for teen clubs are decided by the coordinator together with youth leaders, in accordance with issues raised in previous discussions. Usually, one of the most critical points to deal with is disclosure of HIV status, as many adolescent patients are not aware of their condition. This factor can negatively affect compliance and retention. Hence, disclosure is one of the most delicate subjects to discuss either in personal counselling sessions or in groups.

Furthermore, regular meetings are organised to plan awareness campaigns, such as conferences in secondary schools, where the adolescents themselves are guest speakers. All patients aged 10 19 years are invited to join the programme. The idea is to include them in events at the centre so as to make them protagonists of the care process and enhance adherence to the programme.

\section{Methods}

In the study, all medical records of in-care patients aged 10 - 19 years on 17 December 2016 were included. For each patient, baseline routine data were collected: sex, age, weight, height, haemoglobin (HGB) level and CD4 count. The outcome data were collected one year after the start of the new service. The censoring date was 1 January 2018. The outcome data obtained were weight, height, HGB level, viral load (VL) and follow-up status.

Nutritional status was calculated using body mass index (BMI)for-age $z$-scores (BAZ). BAZ was calculated by the LMS $(\lambda, \mu$ and $\sigma$ ) method $^{[25]}$ using patients' anthropometric data from the electronic medical records; lambda, mu and sigma values were derived from the World Health Organization (WHO) BMI-for-age tabs. ${ }^{[2]}$ Patients with $\mathrm{BAZ}<-2$ were considered malnourished; BAZ between -2 and +2 was normal; and BAZ $>+2$ was overweight. ${ }^{[27,28]}$

All routine laboratory examinations in the study (biochemistry, full blood count, HGB count, CD4 count and VL) were performed in the DREAM laboratory at the same health centre. Laboratory results are routinely entered in the electronic medical record system used in the centre.

Some data were analysed according to age class. In some analyses, the sample was divided into two classes: $10-14$ and $15-19$ years. The cut-off age was selected based on in-the-field experience, as the two classes show different psychosocial characteristics. In other analyses, the sample was divided into five classes (two years per class). Then, $\mathrm{BAZ}$ and HGB level were compared before and after the intervention in various age classes.

According to the WHO, viral suppression is defined as VL $<1000$ copies/mL. ${ }^{[29]} \mathrm{VL}$ was evaluated according to age classes. Follow-up status was defined as follows: in-care, transferred-out, died, or lost to follow-up (LTFU).

Transferred-out patients were those who requested to be followedup in other facilities and received a transfer master card.

LTFU patients were defined as missing patients if they had not reported to the centre $>2$ months after the scheduled appointment. All missing patients were actively tracked, so patients who had possibly died were recorded as death cases.

Factors related to follow-up status, nutritional and haematological improvement, and viral suppression were analysed.

The $\chi^{2}$ and Fisher exact tests were used for categorical variables. Student's $t$-test was used for continuous variables. SPSS software (IBM Corp., USA) was used in the analysis, with a 0.05 significance level.

Ethical approval of the protocol was obtained from the District Health Officer in Blantyre, Malawi (ref. no. BT DHO/MED/9). As this study used routinely collected secondary data, patient informed consent was not required.

\section{Results \\ Baseline}

Baseline data are presented in Table 1. On 17 December 2016, 425 patients aged 10 - 19 years were in the care of the site. The pathway and time of infection for each participant was not assessed. Of these, $202(47.5 \%)$ were female. Their median (interquartile (IQR)) age was $13.6(12.1-15.8)$ years. The median (IQR) follow-up duration before the intervention was 8 (5.2 - 9.3) years.

At baseline, the median (IQR) BAZ was -0.80 (12.1 - 15.8), with no differences between age classes.

Furthermore, $11.1 \%(n=47 / 425)$ of patients were malnourished. Patients aged 16 - 19 years and male patients were more likely to be malnourished $(16.7 \%(n=16 / 96)$, and $16.6 \%(n=37 / 223)$, respectively) than younger and female patients $(9.4 \%(n=31 / 329)$ and $5.0 \%(n=10 / 202)$, respectively). In the Cox regression model, only sex was independently associated with malnutrition $(p=0.000$; $\exp [\mathrm{B}] 0.27)$. Only $6.5 \%(n=6 / 92)$ of patients aged $10-11$ years were malnourished, whereas malnutrition was noted in $18.8 \%$ $(n=3 / 16)$ of patients aged $18-19$ years (Fig. 1). 


\begin{tabular}{|c|c|c|c|c|}
\hline Features & Overall $(N=425)$ & $10-15$ years $(n=329)$ & $16-19$ years $(n=96)$ & $p$-value \\
\hline Female rate, $\%$ & 47.50 & 49.20 & 41.70 & \\
\hline Age (years), median (IQR) & 13.6 (IQR 12.1 - 15.8) & - & - & \\
\hline BAZ & $-0.80(-1.45--0.26)$ & $-0.80(-1.36--0.27)$ & $-0.79(-1.66--0.17)$ & - \\
\hline Malnutrition rate (\%) & 11.10 & 9.40 & 16.70 & OR $1.9(1.002-3.690)$ \\
\hline $\begin{array}{l}\text { Haemoglobin }(\mathrm{mg} / \mathrm{dL}) \text {, } \\
\text { median (IQR) }\end{array}$ & $12.5(11.6-13.4)$ & $12.4(11.6-13.2)$ & $13.1(11.9-14.3)$ & $<0.005$ \\
\hline $\begin{array}{l}\text { CD4 count (cells/ml), } \\
\text { median (IQR) }\end{array}$ & $685(474-984)$ & $773(489-1032)$ & $555(344-673)$ & $<0.000$ \\
\hline
\end{tabular}

The median baseline HGB level was 12.5 $\mathrm{mg} / \mathrm{dL}$ (IQR 11.6 - 13.4). A difference was observed between age categories and sexes. The median HGB levels in patients aged 10 - 15 years and female patients were significantly lower than those in older $(12.4 \mathrm{mg} / \mathrm{dL}$ v. $13.1 \mathrm{mg} / \mathrm{d}$;, $p<0.005)$ and male patients $(12.1 \mathrm{mg} / \mathrm{dL}$ v. $12.8 \mathrm{mg} / \mathrm{dL}$; $p<0.005)$.

The CD4 count was higher in younger patients. The median (IQR) CD4 count was 685 (474 - 984) cells/ $\mu \mathrm{L}$ in the overall sample, 773 (489 - 1 032) cells/ $\mu \mathrm{L}$ in the group aged $10-15$ years and $555(344-673$ cells/ $\mu \mathrm{L})$ in the group aged $16-19$ years $(p<0.000)$.

No differences in CD4 count were observed between sexes.

In all in-care patients, the median (IQR) time of assistance before starting the new service was 96 (62 - 112) months. Each patient was followed-up for one year, up to the censor date. The total follow-up duration was 413 person-years.

\section{Outcomes}

Outcome data are shown in Table 2. The cumulative follow-up duration was 411 person-years. At the end of period (EOP), $403(94.8 \%)$ patients were still in care, 7 (1.6\%) were LTFU, 2 (0.5\%) had died, and 13 (3.1\%) had been transferred to other facilities.

The overall death and LTFU rates were $0.72 / 100$ person-years and 2.9/100 personyears, respectively. Clinical conditions at the start of service were correlated with retention in care, although it was not significant. Retained patients were more likely malnourished $(95.0 \%$ v. $93.6 \%)$ and had a HGB level $<11 \mathrm{mg} / \mathrm{dL}$ ( $98.2 \%$ v. $93.2 \%)$.

Of the patients still in care at the EOP, 50.6\% ( $n=198 / 391)$ had an improvement in BAZ. The improvement was higher in patients aged 15 - 19 years (odds ratio (OR) $2.21(1.43-3.39))$.

Fig. 2 shows how different age classes had different BAZ improvements during



Fig. 1. Rates of wasted patients at baseline for age classes.

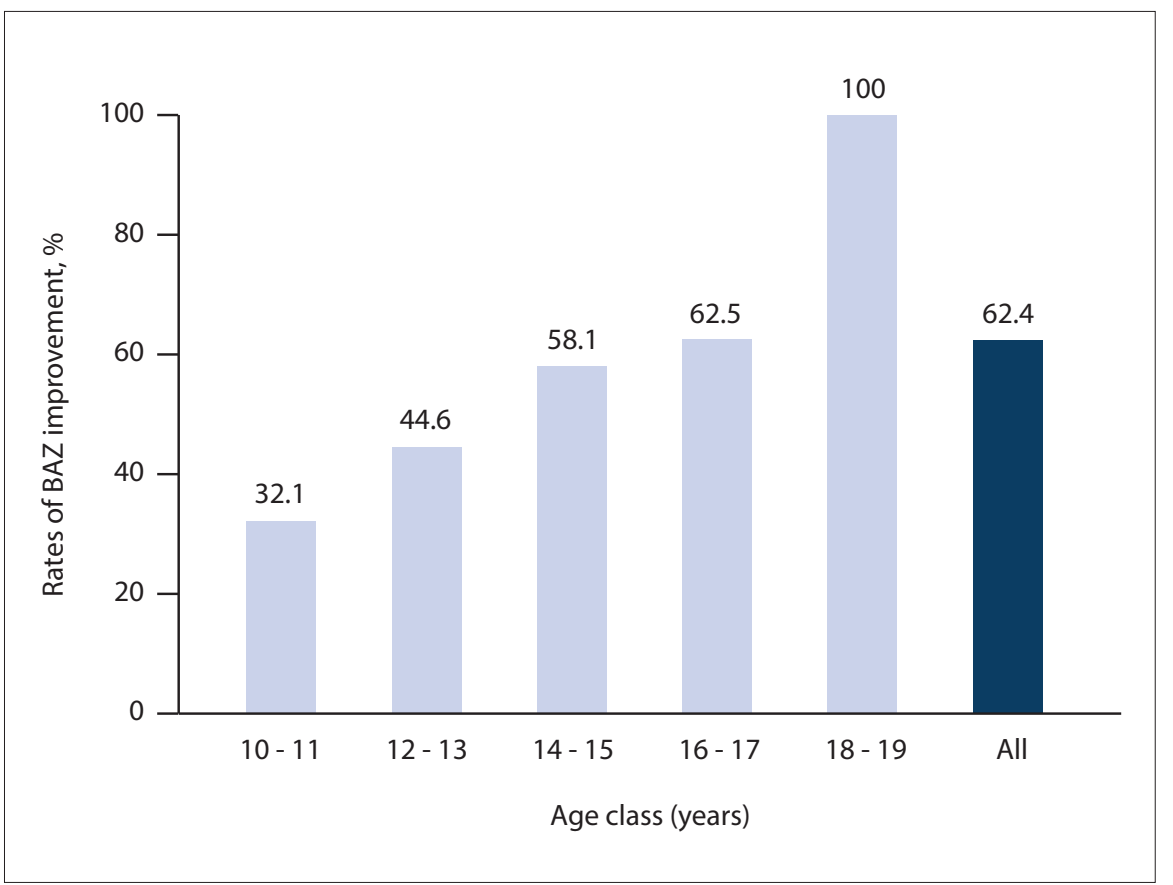

Fig. 2. Rates of BAZ improvement at $E O P$ for age classes. $(B A Z=B M I$-for-age $\mathrm{Z}$-score; $E O P=$ end of period. $)$ 
Table 2. Outcome status at EOP

\begin{tabular}{ll}
\hline Outcome status & $n(\%)$ \\
\hline In care & $403(94.8)$ \\
LTFU & $7(1.6)$ \\
Transfer & $13(3.1)$ \\
Death & $2(0.5)$ \\
EOP = end of period; LTFU = lost to follow-up. &
\end{tabular}

the observation period. Younger patients ( $n=26 / 81$ patients) had a lower improvement than older patients ( $n=15 / 15$ patients). The improvement was significantly higher in patients who were malnourished at baseline than patients who were not initially malnourished (OR 2.7 (1.40 - 5.12)).

All patients who were malnourished at baseline were in care at EOP. Of these, $70.2 \%(n=33 / 47)$ showed nutritional improvement at EOP.

The median (IQR) HGB level at EOP was 13.1 (12.0 - 14.4) mg/dL. A difference was observed between age groups $(12.9 \mathrm{mg} / \mathrm{dL}$ in patients aged $10-14$ years v. $13.6 \mathrm{mg} / \mathrm{dL}$ in patients aged $15-19$ years; $p<0.005)$ and sexes $(13.8 \mathrm{mg} / \mathrm{dL}$ in male patients $\mathrm{v} .12 .6 \mathrm{mg} / \mathrm{dL}$ in female patients; $p<0.005)$. The median HGB variation from the baseline level was $0.45 \mathrm{mg} / \mathrm{dL}$. An HGB improvement was observed in $67.2 \%$ $(n=227 / 338)$ of patients, with no differences between age classes or sexes. The paired $t$-test showed significant differences in HGB levels at EOP, although with scarce relevance at a clinical level (12.5 (1.5) $\mathrm{mg} / \mathrm{dL}$ v. 13.1 (1.9) $\mathrm{mg} / \mathrm{dL} ; p=0.000)$.

At EOP, $79.0 \%(n=309 / 391)$ of patients had viral suppression. No difference was observed between age classes or sexes.

\section{Discussion}

Our study showed a prevalence of malnutrition of $11.1 \%$ at baseline in adolescents, which was particularly low among girls (5.0\%). These data are slightly lower than those presented in 2018 by the Malawian government, ${ }^{[30]}$ which reported a higher rate of malnutrition $(15.6 \%)$ in adolescent girls. The difference could be explained by the fact that the patients in our study, although being HIV-positive, had been followed-up in an HIV service for a median duration of 8 years. DREAM centres also provide nutritional supplementation when needed. Nevertheless, such a high overall malnutrition rate requires particular attention and specific interventions.

In our sample, the malnutrition rate was higher in male patients. This is inconsistent with reports of gender inequality in health and nutrition in Malawi and Africa, and can be explained by the lower adherence rate in older male patients, as reported in other studies, ${ }^{[31]}$ which could negatively affect the nutritional status of the sample.

The Malawi Micronutrient Survey, ${ }^{[30]}$ which shows the anaemia rates in children and young women, reported that $13.1 \%$ of patients had HGB levels $<12 \mathrm{mg} / \mathrm{dL}$ in the age group $11-14$ years. In our cohort, $50 \%$ of patients aged $10-15$ years had HGB levels $<12.4 \mathrm{mg} / \mathrm{dL}$. The survey revealed differences in regional prevalence of anaemic conditions and does not take HIV status into account. These two factors (regional disparities in anaemia prevalence and HIV infection) could explain the higher incidence of low HGB levels.

The CD4 count was high, consistent with the fact that all patients were in care for a median duration of 96 months. Older patients had significantly lower CD4 counts, showing a possible impact of worse retention in such age classes. Other authors have also reported an association between immunological reconstitution during ART and age, ${ }^{[32,33]}$ which could also explain the differences in CD4 count between age classes in our sample.

Retention was high in our sample. Although other studies showed high retention rates, ${ }^{[31,34]}$ this is still a problem in African health systems. ${ }^{[35]}$ In our study, retention was not calculated after the first year of ART but as a cumulative variable regardless of the time of ART. This could be a limitation of our analysis but can also provide a snapshot of the situation in the field that is more consistent with clinical practice. The present results of retention in care are encouraging, but the small sample size did not allow identification of profiles of patients in need of special focus; this could be addressed in further studies.

Outcomes in terms of nutritional rehabilitation and improvement in HGB level suggest the importance of a specific focus on adolescents. Although adolescent patients were already receiving ART with no specific nutritional intervention, the introduction of a specific adolescent-friendly programme improved general conditions.

Different studies reported a wide spectrum of viral suppression rates in adolescents according to different settings and service designs, ranging from $27 \%$ to $89 \%$ after one year of ART. ${ }^{[36]}$ Our result of $79 \%$ for viral suppression is in line with other findings ${ }^{[37,38]}$ and suggests the effectiveness of specific interventions and the need to enhance efforts to reach the third 90 target. ${ }^{[39]}$

The main limitation of our study is insufficient appropriate data pre- and post-intervention, which is due to the retrospective study design, derived from an operational project. Further studies could be conducted in a more controlled setting, with the availability of more organised data, with the possibility to compare pre- and postintervention measurements (including VL). The absence of a control group is also a relevant limitation. Our study is a retrospective analysis of data from a centre devoted to HIV care, and hence the enrolment of HIV-negative adolescents was not possible. Another limit is the size of the sample analysed. Additional studies could help to profile adolescent patients in need of specific interventions.

Notwithstanding these limitations, our study has the merit of describing a complex model of care for adolescents and the effect of its implementation. The combination of clinical, psychological and social support, as described above, could have been the key to the positive impact on follow-up and nutritional conditions. Our results suggest that a combined approach, although harder to assess, could be more effective.

\section{Conclusions}

Data from the DREAM programme show the effectiveness of a public health approach to HIV-positive adolescents' health in Malawi. The results in terms of nutritional rehabilitation, HGB level increase, retention in care, and viral suppression highlight that specific adolescent-friendly interventions are urgently needed to reduce the burden of HIV infection in African adolescents.

\section{Declaration. None.}

Acknowledgements. None.

Author contributions. Data curation: FC and JBS; formal analysis: FC; methodology: FC, SO, MK, JG, MCM, LP; project administration: JBS, MK, JG; resources: RL; supervision: MCM, LP; validation: RL; writing of original draft: FC, MK.

Funding. None.

Conflicts of interest. None. 
1. UNICEF. Key HIV epidemiology indicators for children and adolescents aged 0-19, 2000-2018. New York: UNICEF; 2019.

2. UNAIDS. Ending the AIDS epidemic for adolescents, with adolescents. Joint United Nations Programme on HIV/AIDS; 2016. Geneva: UNAIDS; 2016.

3. Kharsany AB, Karim QA. HIV infection and AIDS in Sub-Saharan Africa: Current status, challenges and opportunities. Open AIDS J 2016;10:34-48. https://doi.org/10.2174\%2F1874613601610010034

4. Ford N, Darder M, Spelman T, Maclean E, Mills E, Boulle A. Early adherence to antiretroviral medication as a predictor of long-term HIV virological suppression: Five-year follow up of an observational cohort. PLoS One 2010;5(5):e10460. https://doi.org/10.1371/journal.pone.0010460

5. Boulle A, Schomaker M, May MT, et al. Mortality in patients with HIV1 infection starting antiretroviral therapy in South Africa, Europe, or North America: A collaborative analysis of prospective studies. PLoS Med 2014;11(9):e1001718. https://doi.org/10.1371/journal.pmed.1001718

6. Enane LA, Vreeman RC, Foster C. Retention and adherence: Global challenges for the long-term care of adolescents and young adults living with HIV. Curr Opin HIV AIDS 2018;13(3):212-219. https://doi.org/10.1097/ coh.0000000000000459

7. Kim SH, Gerver SM, Fidler S, Ward H. Adherence to antiretroviral therapy in adolescents living with HIV: Systematic review and meta-analysis. Aids 2014:28(13):1945-1956. https://doi.org/10.1097/qad 0000000000000316

8. Chandwani S, Koenig LJ, Sill AM, Abramowitz S, Conner LC, D’Angelo L. Predictors of antiretroviral medication adherence among a diverse cohort of adolescents with HIV. J Adolesc Health 2012;51(3):242-251. https://doi. org/10.1016/j.jadohealth.2011.12.013

9. Ndiaye M, Nyasulu P, Nguyen $\mathrm{H}$, et al. Risk factors for suboptimal antiretroviral therapy adherence in HIV-infected adolescents in Gaborone, Botswana: A pilot cross-sectional study. Patient Prefer Adherence 2013;7:891-895. https://doi. org/10.2147\%2FPPA.S47628

10. Auld AF, Agolory SG, Shiraishi RW, et al. Antiretroviral therapy enrollment characteristics and outcomes among HIV-infected adolescents and young adults compared with older adults--seven African countries, 2004-2013. MMWR Morb Mortal Wkly Rep 2014;63(47):1097-1103.

11. Paterson DL, Swindells S, Mohr J, et al. Adherence to protease inhibitor therapy and outcomes in patients with HIV infection. Ann Intern Med 2000;133(1):2130. https://doi.org/10.7326/0003-4819-133-1-200007040-00004

12. Bangsberg DR, Perry S, Charlebois ED, et al. Non-adherence to highly active antiretroviral therapy predicts progression to AIDS. Aids 2001;15(9):11811183. https://doi.org/10.1097/00002030-200106150-00015

13. Palombi L, Bernava GM, Nucita A, et al. Predicting trends in HIV-1 sexual transmission in sub-Saharan Africa through the Drug Resource Enhancement Against AIDS and Malnutrition model: Antiretrovirals for 5 reduction of population infectivity, incidence and prevalence at the district level. Clin Infect Dis 2012;55(2):268-275. https://doi.org/10.1093/cid/cis380

14. Granich RM, Gilks CF, Dye C, De Cock KM, Williams BG. Universal voluntary HIV testing with immediate antiretroviral therapy as a strategy for elimination of HIV transmission: A mathematical model. Lancet 2009;373(9657):48-57. https://doi.org/10.1016/s0140-6736(08)61697-9

15. UNAIDS. Country factsheets - MALAWI 2018 2019. Available from https:// www.unaids.org/en/regionscountries/countries/malawi.

16. Chesney MA, Ickovics JR, Chambers DB, et al. Self-reported adherence to antiretroviral medications among participants in HIV clinical trials: The AACTG adherence instruments. Patient Care Committee \& Adherence Working Group of the Outcomes Committee of the Adult AIDS Clinical Trials Group (AACTG). AIDS Care 2000;12(3):255-266. https://doi. org/10.1080/09540120050042891

17. Mills EJ, Nachega JB, Bangsberg DR, et al. Adherence to HAART: A systematic review of developed and developing nation patient-reported barriers and facilitators. PLoS Med 2006;3(11):e438. https://doi.org/10.1371/journal. pmed.0030438

18. Kanters S, Park JJ, Chan $\mathrm{K}$, et al. Interventions to improve adherence to antiretroviral therapy: A systematic review and network meta-analysis. Lancet HIV 2017;4(1):e31-e40. https://doi.org/10.1016/s2352-3018(16)30206-5

19. Murray KR, Dulli LS, Ridgeway K, et al. Improving retention in HIV care among adolescents and adults in low- and middle-income countries: A systematic review of the literature. PLoS One 2017;12(9):e0184879. https://doi. org/10.1371/journal.pone.0184879

20. Liotta G, Mancinelli S, Nielsen-Saines K, et al. Reduction of maternal mortality with highly active antiretroviral therapy in a large cohort of HIV-infected pregnant women in Malawi and Mozambique. PLoS One 2013;8(8):e71653. https://doi.org/10.1371/journal.pone.0071653
21. Mancinelli S, Nielsen-Saines K, Germano P, et al. Who will be lost? Identifying patients at risk of loss to follow-up in Malawi. The DREAM Program Experience. HIV Med 2017;18(8):573-579. https://doi.org/10.1111/hiv.12492

22. Marazzi MC, De Luca S, Palombi L, et al. Predictors of adverse outcomes in HIV-1-infected children receiving combination antiretroviral treatment: Results from a DREAM cohort in sub-Saharan Africa. Pediatr Infect Dis J 2014;33(3):295-300. https://doi.org/10.1097/inf.0b013e3182a0994b

23. Ciccacci F, Tolno VT, Doro Altan A, et al. Non communicable diseases burden and risk factors in a cohort of HIV-positive elderly patients in Malawi. AIDS Res Hum Retroviruses 2019;35(11-12):1106-1111. https://doi.org/10.1089/ aid.2019.0125

24. Leone M, Palombi L, Guidotti G, et al. What headache services in subSaharan Africa? The DREAM program as possible model. Cephalalgia 2019;39(10):1339-1340. https://doi.org/10.1177/0333102419849014

25. Cole TJ, Bellizzi MC, Flegal KM, Dietz WH. Establishing a standard definition for child overweight and obesity worldwide: International survey. BMJ 2000;320(7244):1240-1243. https://doi.org/10.1136/bmj.320.7244.1240

26. WHO. Growth reference 5-19 years - BMI-for-age (5-19 years). Geneva: World Health Organization; 2007.

27. De Onis M, Onyango A, Borghi E, Siyam A, Blossner M, Lutter C. Worldwide implementation of the WHO Child Growth Standards. Public Health Nutr 2012;15(9):1603-1610. https://doi.org/10.1017/s136898001200105x

28. WHO. WHO child growth standards and the identification of severe acute malnutrition in infants and children. A joint statement. WHO Child Growth Standards and the Identification of Severe Acute Malnutrition in Infants and Children: A Joint Statement by the World Health Organization and the United Nations Children's Fund. Geneva: World Health Organization; 2009.

29. WHO. Consolidated Strategic Information Guidelines for HIV in the Health Sector. Geneva: World Health Organization; 2015.

30. Malawi Government. National Multi-Sector Nutrition Policy 2018-2022. Blantyre: Department of Nutrition; 2018.

31. Nabukeera-Barungi N, Elyanu P, Asire B, et al. Adherence to antiretroviral therapy and retention in care for adolescents living with HIV from 10 districts in Uganda. BMC Infect Dis 2015;15:520. https://doi. org/10.1186\%2Fs12879-015-1265-5

32. Lewis J, Walker AS, Castro H, et al. Age and CD4 count at initiation of antiretroviral therapy in HIV-infected children: Effects on long-term T-cell reconstitution. J Infect Dis 2012;205(4):548-556. https://doi.org/10.1093/ infdis/jir787

33. Picat MQ, Lewis J, Musiime V, et al. Predicting patterns of long-term CD4 reconstitution in HIV-infected children starting antiretroviral therapy in sub-Saharan Africa: A cohort-based modelling study. PLoS Med 2013;10(10):e1001542. https://doi.org/10.1371\%2Fjournal.pmed.1001542

34. Bygrave H, Mtangirwa J, Ncube K, Ford N, Kranzer K, Munyaradzi D. Antiretroviral therapy outcomes among adolescents and youth in rural Zimbabwe. PloS One 2012;7(12):e52856-e. https://dx.doi. org/10.1371\%2Fjournal.pone.0052856

35. Nyogea D, Mtenga S, Henning $L$, et al. Determinants of antiretroviral adherence among HIV positive children and teenagers in rural Tanzania: A mixed methods study. BMC Infect Dis 2015;15:28. https://doi.org/10.1186/ s12879-015-0753-y

36. Ferrand RA, Briggs D, Ferguson J, et al. Viral suppression in adolescents on antiretroviral treatment: Review of the literature and critical appraisal of methodological challenges. Trop Med Int Health 2016;21(3):325-333. https:// doi.org/10.1111/tmi.12656

37. Jobanputra K, Parker LA, Azih C, et al. Factors associated with virological failure and suppression after enhanced adherence counselling, in children, adolescents and adults on antiretroviral therapy for HIV in Swaziland. PLoS ONE 2015;10(2): https://doi.org/10.1371/journal.pone.0116144

38. Mutwa PR, Boer KR, Rusine J, et al. Long-term effectiveness of combination antiretroviral therapy and prevalence of HIV drug resistance in HIV-1-infected children and adolescents in Rwanda. Pediatr Infect Dis J 2014;33(1):63-69. https://doi.org/10.1097/inf.0b013e31829e6b9f

39. Davies M-A, Pinto J, Bras M. Getting to $90-90-90$ in paediatric HIV: What is needed? J Int AIDS Soc 2015;18(7Suppl 6):20770. https://doi. org/10.7448\%2FIAS.18.7.20770 